\title{
EFFECT OF EGR \& NANOPARTICLES ON PERFORMANCE AND EMISSION CHARACTERISTICS OF A DIESEL ENGINE FUELLED WITH PALM BIODIESEL AND DIESEL BLENDS
}

\section{GANESAN, S*; DINESHBABU MUNUSWAMY**; PRABHU APPAVU*; ARUNKUMAR, T and YUVARAJAN DEVARAJAN*}

\begin{abstract}
This work examines the consequence of employing cerium oxide $\left(\mathrm{CeO}_{2}\right)$ nanoparticles at a different proportion (30 ppm, 60 ppm and $90 \mathrm{ppm}$ ) to palm oil methyl ester and diesel blends (B20) in water-cooled single cylinder four stroke diesel engine. Adding nanoparticles is a strategy to improve the performance and reduce emissions of the biodiesel. Prepared samples are fuelled to diesel engine by admitting exhaust gas recirculation (EGR) of $10 \%$ and $20 \%$ by volume. The main intention of this study is to lessen the nitrogen oxide $\left(\mathrm{NO}_{\mathrm{X}}\right)$ emissions for diesel and biodiesel blends. Experimental results found a significant reduction $\mathrm{NO}_{X^{\prime}}$ carbon monoxide (CO), smoke and hydrocarbon (HC) emissions at $10 \%$ EGR rate. However, brake specific fuel consumption is increased with significant lower brake thermal efficiency by admitting EGR of $20 \%$ by volume. Thus, it can be inferred that EGR of $10 \%$ by volume is an optimal way on reducing harmful emissions without compromising much on performance aspects of biodiesel fuelled diesel engine.
\end{abstract}

\section{Keywords: palm biodiesel, exhaust gas recirculation, engine.}

Date received: 8 March 2018; Sent for revision: 6 April 2018; Received in final form: 17 May 2018; Accepted: 18 December 2018.

\section{INTRODUCTION}

The fuel and energy crisis of the late 2000 and early 2010 as well as accompanying concerns about the depletion of the world's non-renewable resources provided the incentives to seek alternatives to conventional, petroleum-based fuels. As the world

Department of Mechanical Engineering, Vel Tech Rangarajan Dr Sagunthala R\&D Institute for Science and Technology, 60062 Chennai, Tamil Nadu, India. E-mail: dyuvarajan2@gmail.com

** Department of Mechanical Engineering, Panimalar Engineering College, Bangalore Tamil Road, Varadharajapuran Nazarethpeltai, 600123 Chennai, Tamil Nadu, India.

‡ Department of Mechanical Engineering, Sathyabama Institute for Science and Technology, 600119 Chennai, Tamil Nadu, India. reserves of fossil fuels and raw materials are limited, active research interest has been stimulated in nonpetroleum, renewable, and non-polluting fuels. Biofuels are the only alternative energy sources for the foreseeable future and can still form the basis of sustainable development in terms of socioeconomic and environmental concerns (Devarajan et al., 2016). In this context, vegetable oils as fuel for diesel engines are considered. They now occupy a prominent position in the development of alternative fuels. Worldwide vegetable oils are used in compression ignition (CI) engines either as a sole fuel or blended with diesel fuel (Jayaprabakar and Karthikeyan, 2016; Pandian et al., 2017).

Many studies have attempted to decrease the nitrogen oxide $\left(\mathrm{NO}_{x}\right)$ emissions from a biodieselfuelled diesel engine. Devarajan et al. (2016) carried 
out an investigation on a content speed single cylinder diesel engine fuelled with neat biodiesel by adding $2 \%$ ferrofluid as an oxygenated additive. They resulted in $2.7 \%$ increase in $\mathrm{NO}_{\mathrm{x}}$ emission. Yuvarajan et al. (2016) investigated the effect of varying the compression ratio in neat biodiesel fuelled diesel engine. They found that an increase in compression ratio improved the performance aspects with a significant reduction in smoke, carbon monoxide $(\mathrm{CO})$ and hydrocarbon $(\mathrm{HC})$ emissions. However, $\mathrm{NO}_{x}$ emissions found to increase with an increase in compression ratio. Ravikumar and Saravanan (2016) carried out an investigation on a content speed single cylinder diesel engine fuelled with neat yellow grease derived biodiesel by adding $20 \%$ pentanol as an oxygenated additive. They resulted in a $1.6 \%$ increase in $\mathrm{NO}_{x}$ emission by adding pentanol to yellow grease derived biodiesel.

Many investigations were attempted to decrease the $\mathrm{NO}_{\mathrm{x}}$ emissions from biodiesel and diesel blends fuelled diesel engine. Anbarasu and Karthikeyan (2015) performed an experimental study on biodiesel and diesel with the addition of aluminium oxide nanoparticle in direct injection constant speed diesel engine. Aluminium oxide nanoparticle at 250 ppm and 500 ppm is added to methyl esters to view the effects on performance and emission characteristics. The $1.32 \%$ enhancement in brake thermal engine (BTE) was achieved by adding 250 ppm of nanoparticle in biodiesel. Further, $17.5 \%$ and $20 \%$ reduction in $\mathrm{HC}$ and $\mathrm{CO}$ was observed with inclusion of 250 ppm of nanoparticle in biodiesel. The $5 \%$ increase in $\mathrm{NO}_{x}$ emission and $27 \%$ reduction in smoke opacity were observed during the trail. Pandian et al. (2017) investigated the consequence of adding titanium oxide nanoparticles in neat biodiesel. Nanoparticles are added at a proportion of 50 and 100 ppm (mass basis) and fuelled in a constant speed diesel engine to evaluate the performance and emission characteristics. Brake specific fuel consumption (BSFC) was reduced by $1.8 \%$ by adding nanoparticles to the biodiesel. Further, $3.1 \%$ of smoke emission was reduced by incorporating nanoparticles into the biodiesel. Addition of aluminum oxide nanoparticles has significant improvement in heat release rate and brake thermal efficiency with a marginal increase in $\mathrm{NO}_{\mathrm{X}}$ emissions. Anbarasu and Karthikeyan (2016) performed an experimental study on biodiesel and diesel with the addition of cerium oxide nanoparticle in direct injection constant speed compression ignition engine. Cerium oxide $\left(\mathrm{CeO}_{2}\right)$ nanoparticle at $100 \mathrm{ppm}$ and $200 \mathrm{ppm}$ is added to methyl esters to view the effects on performance and emission characteristics. The $2.1 \%$ enhancement in BTE was achieved by adding 200 ppm of cerium nanoparticle in biodiesel. Further, $6.8 \%$ and $11.9 \%$ reduction in $\mathrm{HC}$ and $\mathrm{CO}$ was observed with inclusion of 200 ppm of cerium nanoparticle in biodiesel. The 3.8\% increase in $\mathrm{NO}_{\mathrm{x}}$ emission and $4.8 \%$ reduction in smoke opacity were observed during the trail.

Many works have accomplished in a reasonable reduction in $\mathrm{NO}_{x}$ emission by introducing the exhaust gas recirculation (EGR). EGR is extremely valuable in lowering the oxygen concentration and flame temperature of fuel during combustion thereby lessening the $\mathrm{NO}_{\mathrm{x}}$ emissions (Mahalingam et al., 2018; Murugesan et al., 2013; Pandian et al., 2018; Sajeevan and Sajith, 2016). Nevertheless, there exists a gap in the literature on information related to the effect of EGR on engine pattern of a biodieselfuelled diesel engine by adding nanoparticle. Hence in the present study, the effect of EGR on emission and performance characteristics of biodiesel doped with 30 ppm, 60 ppm and 90 ppm of nanoparticle under two EGR rates of $10 \%$, and $20 \%$ was investigated and compared with neat biodiesel and diesel operation.

\section{MATERIALS AND METHODS}

\section{Preparation of Palm Oil Biodiesel}

The methanolic solution which comprised of $90 \%$ volume of methanol and $10 \%$ of sulphuric acid which were mixed at a molar ratio of 16:1 to the palm oil. This sample was then heated $\left(60^{\circ} \mathrm{C}\right)$ at four different time durations $(30,45,60$ and 90 min) by employing a magnetic stirrer with a hot plate. Based on the results, heating for $45 \mathrm{~min}$ and under $60^{\circ} \mathrm{C}$ were found optimal (Yuvarajan and Ramanan, 2016a, c). The separated biodiesel is washed with warm water at $50^{\circ} \mathrm{C}$ three to four times and later heated to $110^{\circ} \mathrm{C}$ to remove the water. Then, the biodiesel is blended with diesel and designated as B20 (20\% biodiesel $+80 \%$ diesel) and B100 (100\% biodiesel). The $\mathrm{CeO}_{2}$ nanoparticle additive was added to the B20 blend at 30 ppm, 60 ppm, and 90 ppm and dispersed using an ultrasonicator. Finally, all the above blends were introduced in the diesel for analysis. Table 1 shows the properties of the modified fuels and diesel.

\section{Experimental Set-up}

Research type $4.4 \mathrm{~kW}$ immobile engine (speed $=1500 \mathrm{rpm}$; cylinder $=1$; compression ratio= $17.5: 1$ ) was employed to test the fuels. Various parameters of the engine are listed in Table 2. A single rotor eddy current dynamometer having a power, torque and a speed of $800 \mathrm{~kW}, 10000 \mathrm{Nm}$ and $11000 \mathrm{rpm}$ respectively was used in the work. The load on the engine was varied by changing the current which induced a magnetic resistance to the motion of the shaft. All these investigations were performed at steady state conditions for results reliability. Prior to testing, the engine was fuelled with diesel for about 
TABLE 1. PROPERTIES OF THE MODIFIED FUELS AND DIESEL

\begin{tabular}{|c|c|c|c|c|c|}
\hline & Diesel & BD20 & BD20+30 ppm & BD20+60 ppm & $\mathrm{BD} 20+90 \mathrm{ppm}$ \\
\hline$@ 40^{\circ} \mathrm{C}$ in cSt & 2.4 & 3.47 & 3.58 & 3.83 & 3.97 \\
\hline Fire point $\left({ }^{\circ} \mathrm{C}\right)$ & 55 & 60 & 65 & 76 & 87 \\
\hline Calorific value in $\mathrm{kJ} \mathrm{kg}^{-1}$ & 42534 & 41342 & 41402 & 41514 & 41608 \\
\hline
\end{tabular}

\begin{tabular}{cc} 
TABLE 2. SPECIFICATION OF THE ENGINE \\
\hline Type & Four stroke \\
Stroke & $110 \mathrm{~mm}$ \\
Bore & $88 \mathrm{~mm}$ \\
Rated output & $4.4 \mathrm{~kW}$ \\
Rated speed & $1500 \mathrm{rpm}$ \\
Compression ratio & 16.5 \\
Injection timing & $23^{\circ} \mathrm{bTDC}$ \\
Loading device & Electric generator \\
\hline
\end{tabular}

30 min for stabilisation purpose. The experimental work was repeated thrice for maintaining accuracy. Square-root techniques were employed to calculate the uncertainty of measured variables.

\section{RESULTS AND DISCUSSION}

The EGR is the effective method commonly used to reduce $\mathrm{NO}_{x}$ emissions for diesel engines fuelled by biodiesel and diesel fuelled engine. Here in the procedure, the portion of exhaust gas containing carbon dioxide $\left(\mathrm{CO}_{2}\right)$ is recirculated during combustion to facilitate the enhancement in overall specific heat capacity of the gas mixture thereby reducing the temperature during combustion (Mahalingam et al., 2018). The EGR execution is the simplest and cheapest technique for $\mathrm{NO}_{\mathrm{X}}$ reduction in diesel engines. The intake manifold is en-suite with a control valve, which governs the flow rate of gas recirculation. This work employs hot EGR method for reducing the $\mathrm{NO}_{x}$ emissions. EGR flow rate is calculated by measuring the concentration of $\mathrm{CO}_{2}$ in the exhaust and intake manifold (Mahalingam et al., 2018).

The following equation calculates the EGR rate:

$$
\operatorname{EGR}(\%)=\frac{\% \text { of } \mathrm{CO}_{2 \text { intake }}}{\% \text { of } \mathrm{CO}_{2 \text { exhaust }}} \times 100
$$

In the present investigation, exhaust gas analyser is employed to measure the quantity of $\mathrm{CO}_{2}$ passing through the exhaust manifold and tailpipe post-combustion. The EGR is varied in the range of $10 \%$ and $20 \%$ for all modified fuels and results are compared with diesel without EGR.

\section{Characterisation of $\mathrm{CeO}_{2}$ Nanoparticle}

The $\mathrm{CeO}_{2}$ nanoparticle was synthesised through the Solvothermal method. The size of $\mathrm{CeO}_{2}$ nanoparticle was found to be $20 \mathrm{~nm}$. Figure 1 shows the scanning electron microscopy (SEM) and transmission electron microscopy (TEM) image of $\mathrm{CeO}_{2}$ nanoparticle.
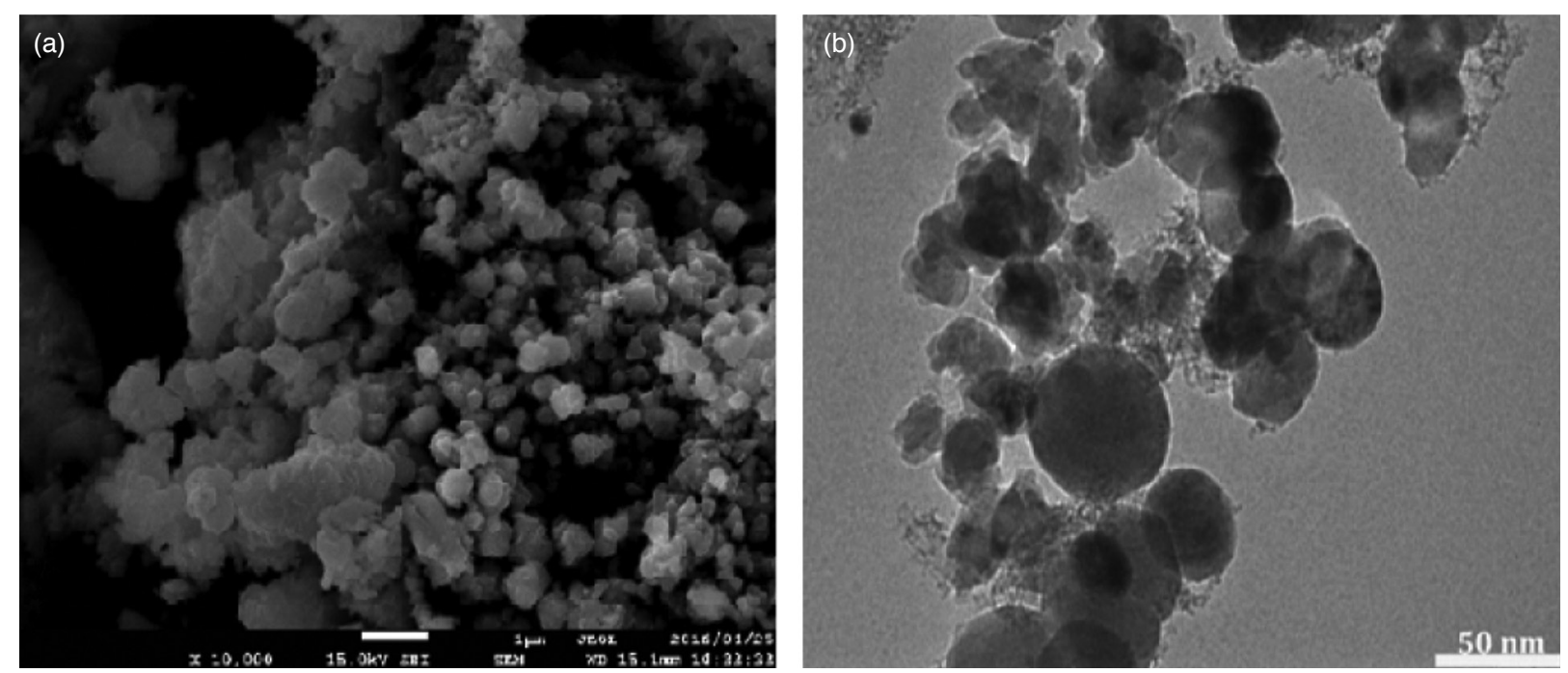

Figure 1. Scanning electron microscopy (SEM) and transmission electron microscopy (TEM) image of alumina nanoparticle. 


\section{Brake Thermal Efficiency}

The deviation of BTE for fuels is shown in Figure 2. The BTE from methyl ester and diesel blends is lesser than diesel (Yuvarajan et al., 2016; Venkata Ramanan and Yuvarajan, 2016). Adding 10, 20 and 30 ppm of $\mathrm{CeO}_{2}$ nanoparticles to BD20 resulted in $0.2 \%, 0.3 \% 0.4 \%$ increases in BTE, respectively, at all loads when compared to neat BD20. The $\mathrm{CeO}_{2}$ nanoparticles cause the complete combustion as it acts as the oxygen donor (Pandian et al., 2017; Anbarasu and Karthikeyan, 2015). Comparative fall in BTE was observed for tested fuels at various fractions of EGR (10\% and 20\% flow rate). Oxygen content in the air reduces with EGR during the combustion and originates poor combustion (Mahalingam et al., 2018; Devarajan et al., 2016; Anbarasu and Karthikeyan, 2016). Lower BTE was observed because of oxygen content and lower combustion temperature of fuels (Devarajan et al., 2017a, c; Mahalingam et al., 2018).

\section{Brake Specific Fuel Consumption}

The deviation of BSFC for tested fuels at various conditions is shown in Figure 3. BSFC from palm oil methyl ester and diesel blends (BD20) is lesser than diesel (Ramanan and Yuvarajan, 2015b; Devarajan et al., 2017b). Adding 10, 20 and 30 ppm of $\mathrm{CeO}_{2}$ nanoparticles to $\mathrm{BD} 20$ resulted in $0.6 \%, 0.8 \%$ and $1.1 \%$ decrease in BSFC, respectively, at all loads when compared to neat BD20. The $\mathrm{CeO}_{2}$ nanoparticles cause complete combustion as it acts as the oxygen donor (Pandian et al., 2017; Jayaprabakar and Karthikeyan, 2016). The $\mathrm{CeO}_{2}$ nanoparticles also enhances the heat transfer rate between the fuel and air and exchange the momentum among the fresh charge and burnt products inside the combustion chamber (Devarajan et al., 2017a; Karthikeyan and Jayaprabakar, 2017). The BSFC for tested fuels reduces at various fractions of EGR $(10 \%$ and $20 \%$ flow rate). The oxygen content in the air reduces with

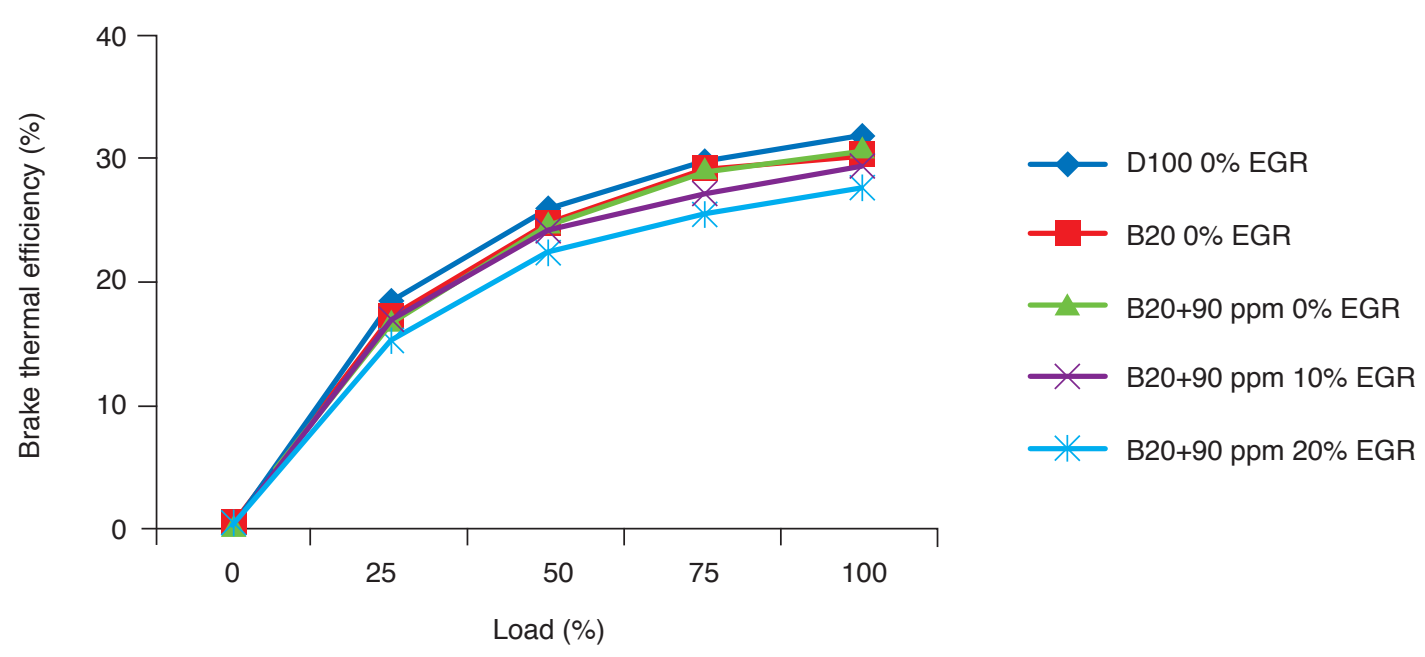

Figure 2. Variation of brake thermal efficiency (BTE) for modified fuels at different exhaust gas recirculation (EGR) rates.

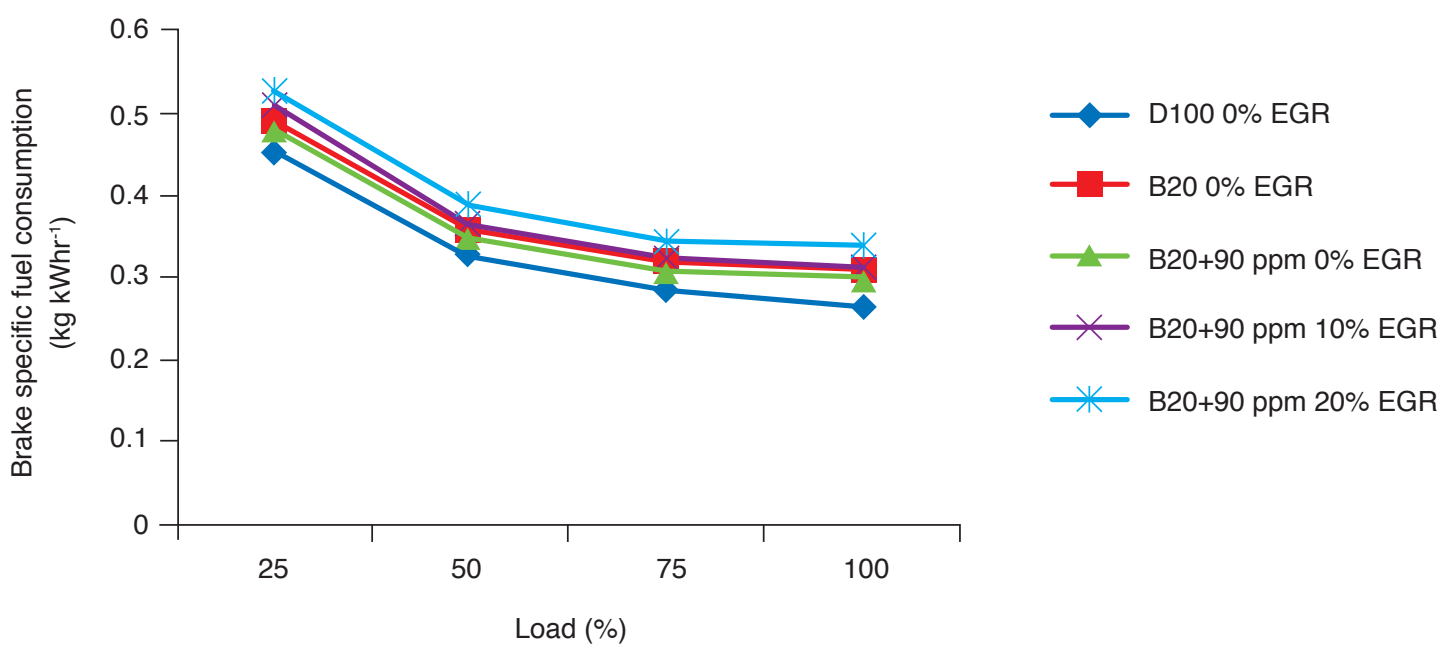

Figure 3. Variation of brake specific fuel consumption (BSFC) for modified fuels at different exhaust gas recirculation (EGR) rates. 
EGR during the combustion and giving rise to poor combustion (Mahalingam et al., 2018; Devarajan et al., 2017a). Lower BSFC was observed because of oxygen content and lower combustion temperature of fuels (Yuvarajan et al., 2016; Mahalingam et al., 2018).

\section{Unburned Hydrocarbon Emissions (UBHC)}

The deviation of hydrocarbon (HC) for fuels is shown in Figure 4. HC emission from palm oil methyl ester and diesel blends is lower than diesel (Devarajan et al., 2017a; Saikrishnan et al., 2017). $\mathrm{HC}$ emission reduces with the addition of $\mathrm{CeO}_{2}$ nanoparticles at various proportions. Adding 10 and 20 and 30 ppm of $\mathrm{CeO}_{2}$ nanoparticles to BD20 resulted in $2.1 \%, 2.9 \%$ and $3.6 \%$ reduction in $\mathrm{HC}$ emissions, respectively, at all loads when compared to neat BD20. The $\mathrm{CeO}_{2}$ nanoparticles increase the combustion efficiency of fuel and promote better combustion and reduce $\mathrm{HC}$ emission (Pandian et al., 2017). The reduction in HC emission was observed for tested fuels at various fractions of EGR (10\% and $20 \%$ flow rate). The oxygen content in the air reduces with EGR during the combustion and originates improved the combustion (Yuvarajan et al., 2017). Lower HC emissions were observed as a result of lower combustion temperature, charge dilution and oxygen content of fuels and improved performance (Mahalingam et al., 2018). Lower $\mathrm{O}_{2}$ content in EGR forms a rich and heterogeneous air-fuel mixture and engenders low HC Emissions (Mahalingam et al., 2018).

\section{Carbon Monoxide (CO) Emissions}

$\mathrm{CO}$ is produced due to deficient fuel combustion. The deviation of $\mathrm{CO}$ for fuels is shown in Figure 5. The $\mathrm{CO}$ emission from palm oil methyl ester and diesel blends is lower than diesel (Devarajan et al.,

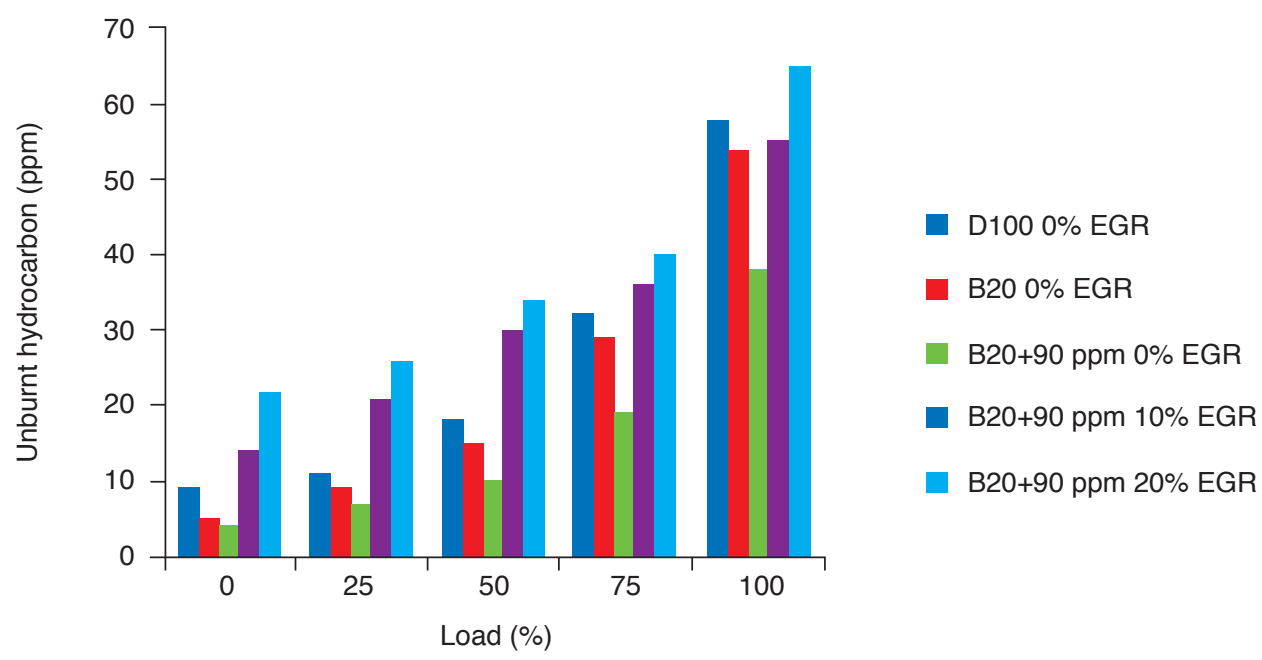

Figure 4. Variation of hydrocarbon (HC) emissions for modified fuels at different exhaust gas recirculation (EGR) rates.

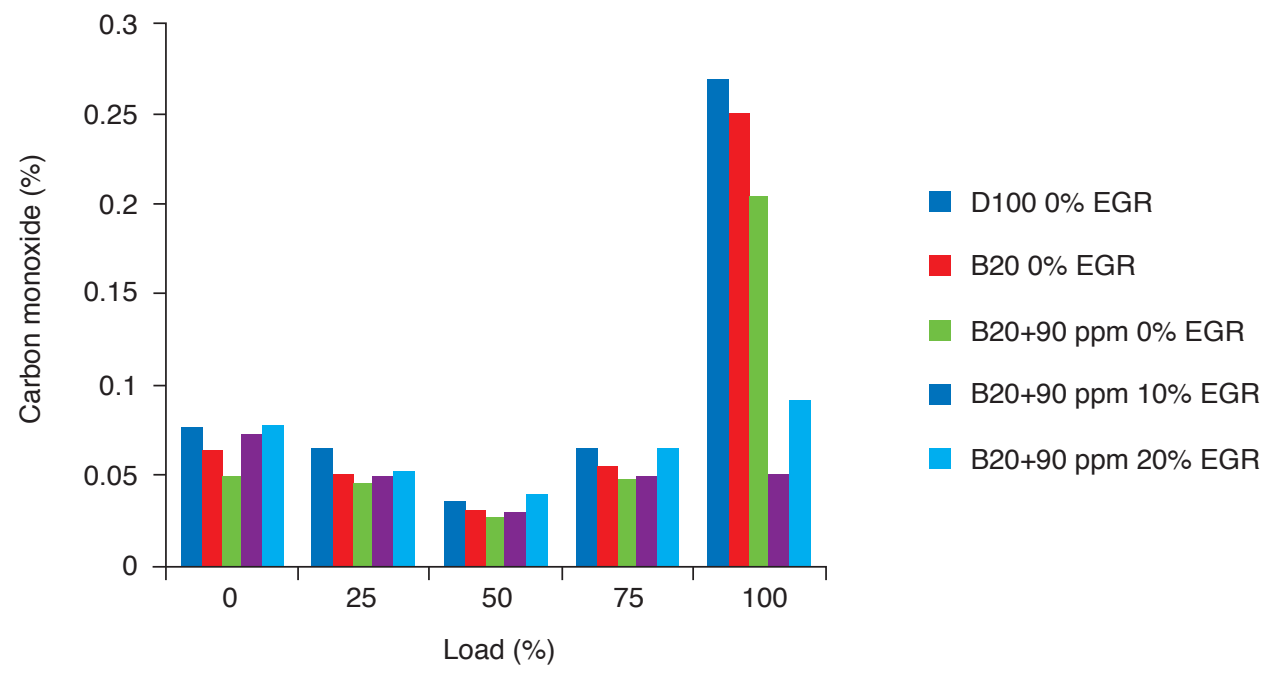

Figure 5. Variation of carbon monoxide (CO) emissions for modified fuels at different exhaust gas recirculation (EGR) rates. 
2017a). The CO emission reduces with the addition of $\mathrm{CeO}_{2}$ nanoparticles at various proportions. Adding 10, 20 and 30 ppm of $\mathrm{CeO}_{2}$ nanoparticles to $\mathrm{BD} 20$ resulted in $3.1 \%, 3.7 \%$ and $4.2 \%$ reduction in $\mathrm{CO}$ emissions, respectively, at all loads when compared to neat BD20. The $\mathrm{CeO}_{2}$ nanoparticles increase the combustion efficiency of fuel and promote the combustion and reduce HC emission (Pandian et al., 2017). The reduction in CO emission was observed for tested fuels at various fractions of EGR (10\% and 20\% flow rate). The oxygen content in the air reduces with EGR during the combustion and gives better combustion (Yuvarajan et al., 2017). Lower $\mathrm{CO}$ emissions were observed as a result of charge dilution, lower combustion temperature and oxygen content of fuels and improved performance (Mahalingam et al., 2018). Lower oxygen content in EGR forms a rich and heterogeneous air-fuel mixture and engenders low $\mathrm{CO}$ emissions (Mahalingam et al., 2018).

\section{Nitrogen Oxide Emissions}

The formation of $\mathrm{NO}_{x}$ emissions during the combustion depends on the availability of residence time and excess oxygen and elevated combustion temperature. The deviation of $\mathrm{NO}_{x}$ for fuels is shown in Figure 6. The $\mathrm{NO}_{\mathrm{x}}$ emission from palm oil methyl ester and diesel blends is higher than diesel (Devarajan et al., 2017a). The $\mathrm{NO}_{\mathrm{x}}$ emission reduces with the addition of $\mathrm{CeO}_{2}$ nanoparticles at various proportions. Adding 10, 20 and $30 \mathrm{ppm}$ of $\mathrm{CeO}_{2}$ nanoparticles to BD20 resulted in 3.1\%, 3.3\% and $3.9 \%$ reduction in $\mathrm{NO}_{\mathrm{x}}$ emissions, respectively, at all loads when compared to neat BD20. The $\mathrm{CeO}_{2}$ nanoparticles in biodiesel and diesel mixture lower the cylinder temperature during combustion by making the air-fuel mixture leaner and thus reducing the $\mathrm{NO}_{x}$ emission. Further, $\mathrm{CeO}_{2}$ nanoparticles increase the combustion efficiency of fuel, promote better combustion, and reduce $\mathrm{NO}_{\mathrm{x}}$ emission (Pandian et al., 2018). EGR introduction at various fractions ( $10 \%$ and $20 \%$ flow rate) results in significant $\mathrm{NO}_{\mathrm{x}}$ emission. Adequate availability of oxygen present in the exhaust gas reduces with EGR during the combustion and gives better combustion (Mahalingam et al., 2018). Lower $\mathrm{NO}_{\mathrm{x}}$ emissions were observed as a result of lesser combustion temperature and oxygen content of fuels (Yuvarajan et al., 2017). Shorter availability of oxygen also causes a reduction in $\mathrm{NO}_{\mathrm{x}}$ (Mahalingam et al., 2018).

\section{Smoke Emissions}

The deviation of smoke emissions for fuels is shown in Figure 7. The smoke emission from palm oil methyl ester and diesel blends is lower than diesel (Devarajan et al., 2017a). The smoke emission reduces with the addition of $\mathrm{CeO}_{2}$ nanoparticles at various proportions. Adding 10, 20 and 30 ppm of $\mathrm{CeO}_{2}$ nanoparticles to BD20 resulted in 5.1\%, 5.9\% and $6.4 \%$ reduction in $\mathrm{NO}_{\mathrm{x}}$ emissions, respectively, at all loads when compared to neat BD20. The oxygen content in $\mathrm{CeO}_{2}$ nanoparticles gets bonded during the phase of combustion and lowers the formation of soot (Devarajan et al., 2016; 2017a). Further, $\mathrm{CeO}_{2}$ nanoparticles increase the combustion efficiency of fuel and promote better combustion and reduce $\mathrm{NO}_{x}$ emission (Pandian et al., 2017). The reduction in smoke emission was observed for tested fuels at various fractions of EGR ( $10 \%$ and $20 \%$ flow rate). The oxygen content in the air reduces with EGR during the combustion and gives better combustion (Yuvarajan et al., 2017). The higher availability of oxygen also causes a reduction in smoke emissions during EGR mode (Mahalingam et al., 2018).

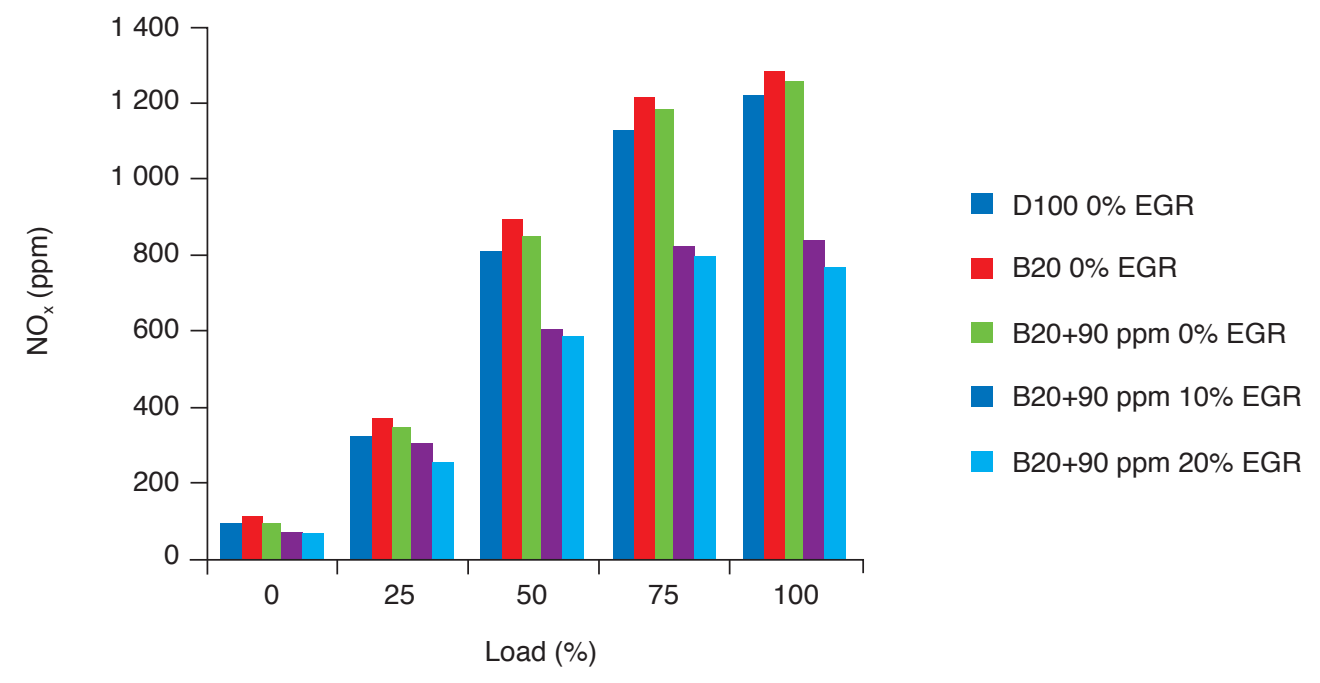

Figure 6. Variation of nitrogen oxide $\left(N O_{X}\right)$ emissions for modified fuels at different exhaust gas recirculation $(E G R)$ rates. 


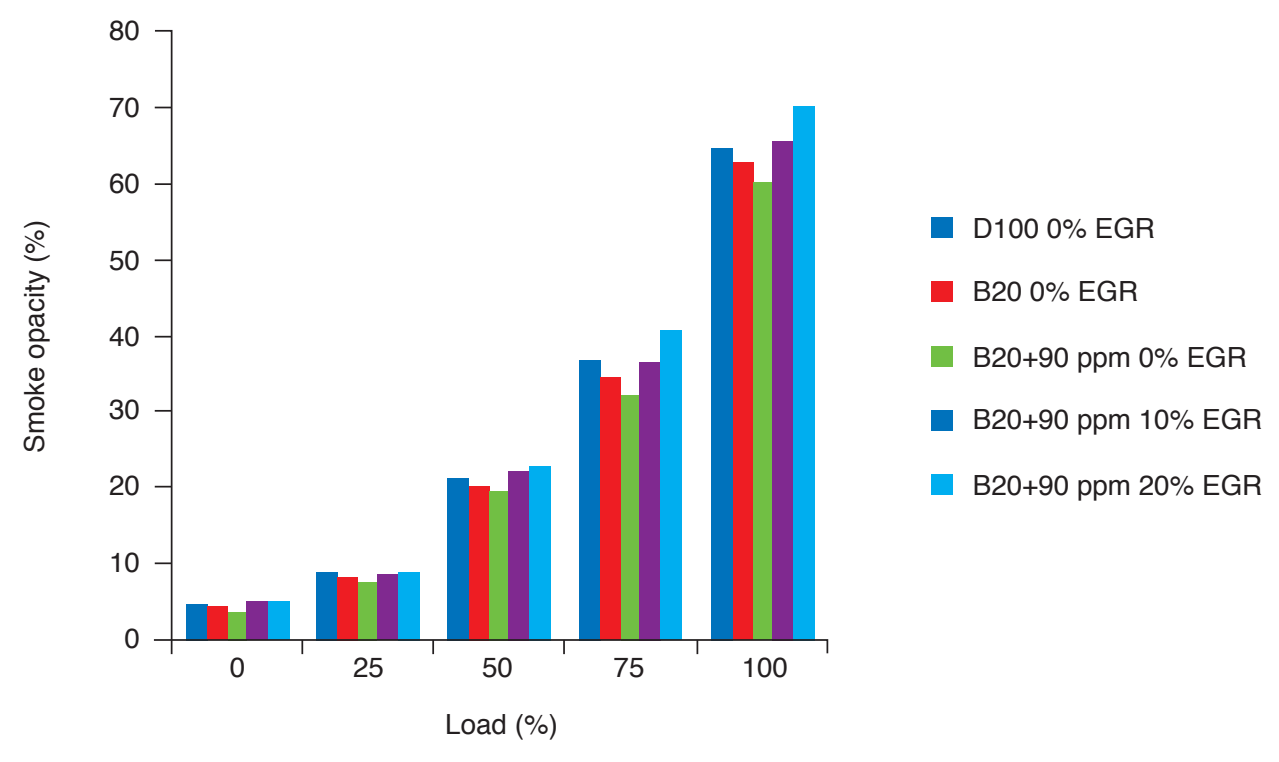

Figure 7. Variation of smoke emissions for modified fuels at different exhaust gas recirculation (EGR) rates.

\section{CONCLUSION}

This work examines the effects of $\mathrm{CeO}_{2}$ nanoparticle on neat palm oil methyl ester and diesel blends on the performance and emissions of the unmodified research engine. Three concentrations of $\mathrm{CeO}_{2}$ nanoparticles are added at 10 and 20 and $30 \mathrm{ppm}$ to palm oil methyl ester and diesel blends respectively and was used as fuel in the research engine at $0 \%, 10 \%$ and $20 \%$ EGR rates. The findings on the engine's emission are as follows:

1. Neat palm oil methyl ester becomes miscible with diesel with no phase separation.

2. Palm oil methyl ester does not require any solvents / surfactants blending with diesel.

3. BTE increased and BSFC reduced with increasing $\mathrm{CeO}_{2}$ nanoparticles fraction in the palm oil methyl ester and diesel blends. Nevertheless, both the parameters suffered at $10 \%$ and $20 \%$ EGR rate.

4. $\mathrm{CO}$ and $\mathrm{HC}$ emissions remained low for neat palm oil methyl ester and diesel blends. A maximum reduction of up to $3.6 \%$ and $4.2 \%$ of $\mathrm{CO}$ and $\mathrm{HC}$ emissions were obtained respectively for BD20. Further, these emissions were reduced with the introduction of EGR.

5. $\mathrm{NO}_{\mathrm{x}}$ and smoke emissions drop drastically with increasing $\mathrm{CeO}_{2}$ nanoparticles concentration. A maximum reduction of up to $3.8 \%$ and $6.4 \%$ of $\mathrm{NO}_{x}$ and smoke emissions were obtained respectively. EGR further reduces the $\mathrm{NO}_{x}$ with a minor increase in other smoke emissions of palm oil methyl ester and diesel blends.

\section{REFERENCES}

Anbarasu, A and Karthikeyan, A (2015). Performance and emission characteristics of diesel engine using alumina oxide nanoparticle blended biodiesel emulsion fuel. J. Energ Res. Technol., 138 (2): 022203.

Anbarasu, A and Karthikeyan, A (2016). Performance and emission characteristics of diesel engine using cerium oxide nanoparticle blended biodiesel emulsion fuel. J. Energ Engg., 142 (1): 04015009.

Devarajan, Y; Jayabal, R K; Ragupathy, D and Venu, H (2016). Emissions analysis on second generation biodiesel. Frontiers Environ. Sci. Eng., 11(1): 3 .

Devarajan, Y; Munuswamy Babu and Nagappan, B (2017a). Emissions analysis on diesel engine fueled with cashew nut shell biodiesel and pentanol blends. Environ. Sci. Pollution Res., 24(14): 13136-13141.

Devarajan, Y; Munuswamy, D B; Mahalingam, A and Nagappan, B (2017b). Performance, combustion, and emission analysis of neat palm oil biodiesel and higher alcohol blends in a diesel engine. Energy $\mathcal{E}$ Fuels, 31(12): 13796-13801.

Devarajan, Y; Munuswamy, D B and Mahalingam, A (2017c). Performance, combustion and emission analysis on the effect of ferrofluid on neat biodiesel. Process Safety and Environmental Protection, 111: 283291. 
Devarajan, Y; Munuswamy, D B; Nagappan, B and Pandian, A K (2018). Performance, combustion and emission analysis of mustard oil biodiesel and octanol blends in diesel engine. Heat and Mass Transfer, 17. DOI:10.1007 / s00231-018-2274-x.

Joy, N; Devarajan, Y; Nagappan, B and Anderson, A (2017). Exhaust emission study on neat biodiesel and alcohol blends fueled diesel engine. Energy Sources, Part A: Recovery, Utilization and Environmental Effects, 40(1): 115-119.

Jayaprabakar, J and Karthikeyan, A (2016). Performance of micro algae methyl esters in a compression ignition engine. J. Balkan Tribological Assoc., 22 (3): 2711-2727.

Karthikeyan, A and Jayaprabakar, J (2017). Energy and exergy analysis of compression ignition engine fuelled with rice bran biodiesel blends. I. J. Ambient Energy: 1-7. DOI: 10.1080/01430750.2017.1399459.

Mahalingam, A; Munuswamy, D B; Devarajan, $Y$ and Radhakrishnan, S (2018). Emission and performance analysis on the effect of exhaust gas recirculation in alcohol-biodiesel aspirated research diesel engine. Environmental Science and Pollution Research, 25(13): 12641-12647. DOI:10.1007/s11356018-1522-4.

Murugesan, A; Subramaniam, D; Avinash, A and Nedunchezhian, N (2013). Quantitative and qualitative analysis of biodiesel - An in-depth study. I. J. Ambient Energy, 36(1): 19-30.

Naik, N S and Balakrishna, B (2017). A comparative study of B10 biodiesel blends and its performance and combustion characteristics. I. J. Ambient Energy: 1-7. DOI:10.1080/01430750.2017.1303629.

Pandian, A K; Ramakrishnan, R B B and Devarajan, $Y$ (2017). Emission analysis on the effect of nanoparticles on neat biodiesel in unmodified diesel engine. Envi. Science Pollution Res., 24(29): 2327323278. DOI:10.1007/s11356-017-9973-6.

Pandian, A K; Munuswamy, D B; Radhakrishanan, S; Devarajan, Y; Ramakrishnan, R B B and Nagappan, B (2018). Emission and performance analysis of a diesel engine burning cashew nut shell oil bio diesel mixed with hexanol. Petroleum Science. DOI:10.1007 / s12182-017-0208-8.

Ravichandra Ganesh, P and Hemachandra Reddy, $K$ (2015). Experimental investigation on the performance and emission characteristics of didiesel engine using diesel-ethanol blends with aqueous cerium oxide nanofluid as additive. Appl. Mech. Mater, 787: 741-745. DOI:10.4028/www. scientific.net/amm.787.741.

Saikrishnan, V; Karthikeyan, A and Jayaprabakar, J (2017). Analysis of ethanol blends on spark ignition engines. Int. J. Ambient Energy, 39(2): 103-107.

Sajeevan, A C and Sajith, V (2016). Synthesis of stable cerium zirconium oxide nanoparticle Diesel suspension and investigation of its effects on diesel properties and smoke. Fuel, 183: 155-163. DOI:10.1016/j.fuel.2016.06.048.

Velmurugan, K and Sathiyagnanam, A P (2016). Effect of biodiesel fuel properties and formation of $\mathrm{NO}_{x}$ emissions: A review. I. J. Ambient Energy, 38(6): 644-651. DOI:10.1080/01430750.2016.1155486.

Yilmaz, N and Atmanli, A (2017). Experimental assessment of a diesel engine fueled with dieselbiodiesel-1-pentanol blends. Fuel, 191: 190-197.

Venkata Ramanan, M and Yuvarajan, D (2016). Emission analysis on the influence of magnetite nanofluid on methyl ester in diesel engine. Atmos. Pollution Res., 7(3): 477-481. DOI:10.1016/j. apr.2015.12.001

Yuvarajan, D; Ravikumar, J and Babu, M D (2016). Simultaneous optimization of smoke and $\mathrm{NO}_{x}$ emissions in a stationary diesel engine fuelled with diesel-oxygenate blends using the grey relational analysis in the Taguchi method. Anal. Methods, 832: 6222-6230.

Yuvarajan, D; Dinesh Babu, M; Beemkumar, N and Amith Kishore, P (2017). Experimental investigation on the influence of titanium dioxide nanofluid on emission pattern of biodiesel in a diesel engine. Atmos. Pollution Res. DOI:10.1016/j.apr.2017.06.003. 